\title{
Responding to students: dependencies on mathematical knowledge and vision
}

\author{
Kim Beswick ${ }^{1}$ \\ Published online: 18 March 2020 \\ (c) Springer Nature B.V. 2020
}

This issue is bookended by articles that examine teachers providing feedback to their students. In the first article Kastberg, Lischka, and Hillman discuss their experiences, as mathematics teacher educators (MTEs), of providing feedback to prospective teachers, while Monson, Krupa, Lesseig, and Casey present the findings of a study of the impacts of an intervention aimed at developing the capacity of secondary prospective teachers to respond to school students' work. The juxtaposition of these articles draws attention to the similarities and differences between the work of mathematics teachers working with school students and mathematics teacher educators working with prospective teachers. This relationship has been characterized as hierarchical (e.g., Leikin et al. 2018) but more than the content to be taught and learned (mathematics compared with mathematics teaching), and the learners (school students compared with prospective teachers of school students) distinguish the two situations (Beswick and Goos 2018). Kastberg et al., for example, note that, in addition to informing prospective teachers about their performance and furthering their learning, MTE feedback constitutes a model of practice from which prospective teachers can learn. These authors contribute to a growing literature contributing to a finegrained understanding of specific aspects of MTEs' work.

Stevens, Wilkins, Lovin, Siegfried, Norton, and Busi report on the apparent impacts on prospective teachers' construction of higher-level fraction schemes and operations of quite small changes to part of a course dealing with number concepts. Specifically, they incorporated a greater focus than previously on improper fractions and shifted the emphasis in the language used from part-whole toward iterative. Their emphasis, as MTEs, on choice of tasks mirrors the importance attached to this ability as an aspect of pedagogical content knowledge for teachers (Chick and Beswick 2018). Although the Stevens et al. are cautious of making causal claims in the absence of a control group, this intervention appeared to be sufficient to have a significant impact.

Jansen, Gallivan, and Miller consider the notion of instructional vision and the extent to which teachers 2-3 years after graduating articulate visions that align with that promoted in their initial teacher education program, namely teaching mathematics for conceptual understanding. Jansen et al. define instructional vision as a future focused ideal image of teaching that can drive change. They regard vision as related to, but more concrete than, beliefs and constituting a part of teachers' identity. Even though the program vision seems

Kim Beswick

k.beswick@unsw.edu.au

1 Sydney, Australia 
to have been implicit, Jansen et al. found that $89 \%$ of the 81 early career elementary teachers who participated in their study had visions for mathematics teaching that aligned with it, but that this could take one of two forms. Based on Ball and Bass's (2000) articulation of pedagogical commitments underpinning constructivist teaching, the authors speculate that the difference between the instructional visions of these two groups could be due to differences in the strength of their commitment to respecting children's mathematical ideas. Unfortunately, $11 \%$ of the teachers shared visions that did not reflect teaching for conceptual understanding. Jansen et al. dismiss these as teachers who were not reached by the program. It would be useful to further explore the reasons for which these teachers seemed inert in relation to the program. There could be implications for both program design and for prospective teacher selection.

Monson et al. address the well-known difficulty that both prospective and practicing teachers have in responding helpfully to students' work, even when they are aware of the likely thinking that led to the work. They describe in detail a specific assignment for prospective teachers along with associated classwork that could be adapted for use with practicing teachers or based on different mathematical tasks for use with either prospective or practicing teachers. Their work illustrates the value of sound theoretical frameworks for underpinning both MTEs and teachers' work. In this case, Monson et al. found Jacob et al.'s (2010) framework for noticing useful and were able elaborate the third aspect of this framework, responding, to scaffold prospective teachers' efforts to propose effective responses to student work. They also highlight the importance of practice to enabling teachers to develop their ability to respond.

The ways in which schoolteachers or MTEs respond to their students' work is underpinned by their own mathematical knowledge and beliefs (used here to include instructional vision as described by Jansen et al.). According to Jansen et al., beliefs change can be supported in four ways. These are in evidence across the articles in this issue. The first is experiencing learning mathematics in new ways in the role of student (Borasi et al. 1999). This was the intention of the initial teacher education program from which the participants in Jansen et al.'s study had graduated. The authors believe that experiencing learning mathematics for conceptual understanding contributed to these teachers having visions for mathematics teaching that included that emphasis. The second is developing teachers' mathematics content knowledge (e.g., Stohlman et al. 2014). This is evident in the article by Stevens et al. in relation to fractions. A third support for beliefs change is becoming aware of and reflecting upon one's beliefs (Tatto 1998). The instructional vision questionnaire used by Jansen et al. would likely serve this purpose or could certainly be used or adapted to elicit beliefs. Finally, Jansen et al. list reflecting on student thinking as a support for belief change, citing Philipp et al. (2007). Developing prospective teachers to move beyond just identifying and interpreting students' thinking was the focus of the work reported by Monson et al. and was also illustrated Kastberg et al.'s account of the authors reflecting on the ways in which they responded to prospective teachers' work. In fact, each paper in this issue arose from the authors reflecting on their practice and seeking either to examine it with a view to achieving greater understanding (Kastberg et al.), modifying elements of courses or programs (Stevens et al.; Monson et al.), or seeking evidence of the impact of their program as a basis for reflection (Jansen et al.). More recent literature has challenged or nuanced some of the supports for beliefs change listed by Jansen et al. and also suggested other catalysts for change (e.g., Liljedahl 2010), but, nevertheless, they offer useful starting points for MTEs to consider in their efforts to influence teachers.

This collection of articles also exemplifies an interesting range of methodologies. Kastberg et al. provide an example of rigorous, theoretical grounded self-study methodology 
of the kind that Chapman et al. (in press) have urged researchers using self-based methodologies to adopt, while Jansen et al.'s detailed coding and subsequent use of latent class analysis to identify different profiles of instructional vision resulted in unique insights. Monson et al. demonstrate the power of collaborating across institutions using a theoretical framework that was able to be applied to similar but nonidentical tasks. Setting up such collaborations supports consideration of the extent to which frameworks translate across contexts and contributes to research on teacher education being far more than an individual (researcher or institution) pursuit. These articles are further evidence of maturation of the field along the lines followed in research on school mathematics teaching, toward more detailed and fine-grained considerations that elevate the work of MTEs above intuitive application of school teaching capacities to teacher audiences.

\section{References}

Ball, D. L., \& Bass, H. (2000). Making believe: The collective construction of public mathematical knowledge in the elementary classroom. In D. Phillips (Ed.), Yearbook of the National Society for the Study of Education, constructivism in education (pp. 193-224). Chicago: University of Chicago Press.

Beswick, K., \& Goos, M. (2018). Mathematics teacher educator knowledge: What do we know and where to from here? Journal of Mathematics Teacher Education, 21(5), 417-427.

Borasi, R., Fonzi, J., Smith, C. F., \& Rose, B. J. (1999). Beginning the process of rethinking mathematics instruction: A professional development program. Journal of Mathematics Teacher Education, 2(1), 49-78.

Chapman, O., Kastberg, S., Suarzo-Flores, E., Cox, D., \& Ward, J. (in press). Mathematics teacher educators' learning through self-based methodologies. In K. Beswick, \& O. Chapman (Eds.), International handbook of mathematics teacher education: Volume 4: The mathematics teacher educator as a developing professional (2nd ed.). Leiden: Brill Sense.

Chick, H., \& Beswick, K. (2018). Teaching teachers to teach Boris: A framework for mathematics teacher educator pedagogical content knowledge. Journal of Mathematics Teacher Education, 21(5), 475-499.

Jacobs, V. R., Lamb, L. L., \& Philipp, R. A. (2010). Professional noticing of children's mathematical thinking. Journal for Research in Mathematics Education, 41, 169-202.

Leikin, R., Zazkis, R., \& Meller, M. (2018). Research mathematicians as teacher educators: Focusing on mathematics for secondary mathematics teachers. Journal of Mathematics Teacher Education, 21(5), $451-473$.

Liljedahl, P. (2010). Noticing rapid and profound mathematics teacher change. Journal of Mathematics Teacher Education, 13, 411-423.

Philipp, R. A., Ambrose, R., Lamb, L. L. C., Sowder, J. T., Schappelle, B. P., Sowder, L., et al. (2007). Effects of early field experiences on the mathematical content knowledge and beliefs of prospective elementary school teachers: An experimental study. Journal for Research in Mathematics Education, $38(5), 438-476$.

Stohlman, M., Cramer, K., Moore, T., \& Maiorca, C. (2014). Changing prospective elementary teachers' beliefs about mathematical knowledge. Mathematics Teacher Education and Development, 16(2), 4-24.

Tatto, M. T. (1998). The influence of teacher education on teachers' beliefs about the purposes of education, roles, and practice. Journal of Teacher Education, 49(1), 66-77.

Publisher's Note Springer Nature remains neutral with regard to jurisdictional claims in published maps and institutional affiliations. 